BULLETIN Bulletin hispanique

HispaniQuE Université Michel de Montaigne Bordeaux

109-2 | 2007

La formation du Parnasse espagnol XVe-XVIII ${ }^{\mathrm{e}}$ siècle

\title{
Juan Francisco Andrés de Uztarroz y el Parnaso femenino en Aragón
}

\section{Carmen Marín Pina}

\section{OpenEdition}

Journals

\section{Edición electrónica}

URL: http://journals.openedition.org/bulletinhispanique/328

DOI: 10.4000/bulletinhispanique.328

ISSN: 1775-3821

\section{Editor}

Presses universitaires de Bordeaux

\section{Edición impresa}

Fecha de publicación: 1 diciembre 2007

Paginación: 589-614

ISBN: 978-2-85276-096-7

ISSN: 0007-4640

\section{Referencia electrónica}

Carmen Marín Pina, « Juan Francisco Andrés de Uztarroz y el Parnaso femenino en Aragón », Bulletin hispanique [En línea], 109-2 | 2007, documento 11, Publicado el 01 diciembre 2010, consultado el 19 abril 2019. URL : http://journals.openedition.org/bulletinhispanique/328 ; DOI : 10.4000/ bulletinhispanique.328 


\title{
Juan Francisco Andrés de Uztarroz y el Parnaso femenino en Aragón ${ }^{1}$
}

\author{
Carmen Marín Pina \\ Universidad de Zaragoza - España
}

En Aragon, le Parnasse féminin se constitue, au milieu du XVII siècle, autour de la figure de Juan Francisco Andrés de Uztarroz. En s'appuyant sur les concours de poésie pour lesquels il est intervenu et auxquels ont participé des femmes, ainsi que sur les correspondances conservées, on étudie les mécanismes de canonisation de quelques unes des auteures avec lesquelles le poète-chroniqueur a entretenu une relation littéraire.

El Parnaso femenino en Aragón se configura a mediados del siglo XVII en torno a la figura de Juan Francisco Andrés de Uztarroz. A partir de los certámenes poéticos en los que participó y concurrieron mujeres y de las cartas conservadas, se estudian los mecanismos de canonización de algunas de las escritoras con las que el poeta y cronista mantuvo una relación literaria.

The feminine Parnassus in Aragon was established around Juan Francisco Andrés de Uztarroz in the mid seventeenth century. The ways in which these aragonese women writers connected with the poet and chronicler became part of the canon are analysed on the basis of poetical contests in which they participated, the sentences which were then pronounced and preserved personal letters.

Mots-clés : Écriture féminine - Parnasse - Canon - Correspondances - Concours poétiques.

1. Este trabajo se inscribe en el Proyecto de Investigación «Bibliografía de escritoras españolas (Edad Media-Siglo XVIII). II», (MUM 2006-03215) del Ministerio de Educación, Ciencia y Tecnología. Sus planteamientos se consideran complementarios de los que presenta también en este volumen el trabajo de Nieves Baranda.

$B H i$, Tome 109, nº 2 - décembre 2007 - p. 589 à 614. 
T Egar hasta el Parnaso no estaba al alcance de todos y menos de $\mathcal{L}$ las mujeres. En su Viaje del Parnaso (Madrid, 1614), Cervantes no llevó a ninguna mujer poeta ${ }^{2}$, Lope de Vega en el Laurel de Apolo (1630) dio pasaje a menos de una decena ${ }^{3}$ y en los certámenes poéticos locales sólo algunas privilegiadas alcanzaron laureles. Rescatar del olvido a todas estas poetas que lograron pisar las faldas o la cumbre del sagrado monte, representación de la meta y de la consagración del poeta ${ }^{4}$, es un paso más para reconstruir la historia de la escritura femenina y para descubrir una parte ignorada de la poesía española. Desde una concepción historicista del canon y con la convicción de que tan importante es conocer el canon establecido como redescubrir el de los autores o grupos excluidos ${ }^{5}$, voy a

2. Aunque no hay noticias de cuál fue el conocimiento que Cervantes tenía de la poesía femenina, posiblemente los versos de estas poetas, en muchos casos ocasionales y aficionadas, no cuadraban con su noble concepto de la poesía y, como dice el paje de La Gitanilla, «ese nombre de poeta muy pocos le merecen». Recuérdese que en el prólogo del Quijote, al hablar de los versos iniciales, Cervantes rechaza incluir sonetos en los preliminares "cuyos autores sean duques, marqueses, condes, obispos, damas o poetas celebérrimos». Ambos pasajes los recoge Vicente Gaos en el apéndice «Poética de Cervantes» a su edición del Viaje del Parnaso. Poesías completas, I, Madrid, Castalia, 1984, pp. 192 y 197. Sobre su consideración de la poesía en relación con el canon, véase Pedro Ruiz, «El Parnaso se desplaza: entre el autor y el canon», En torno al canon: aproximaciones y estrategias, ed. Begońa López Bueno, Sevilla, Universidad de Sevilla, Grupo PASO, 2005, pp. 197-232.

3. Lope de Vega en su Laurel de Apolo, 1629, ed. facsímil en Colección de las obras sueltas, asi en prosa como en verso, tomos I-XXI, Madrid, Arco/Libros, 1989, cita a Clara Barrionuevo, Isabel de Rivadeneyra, Laurenzia de Zurita, Ana de Castro (silva I), Cristobalina [Fernández de Alarcón], Juliana Morella (silva II), Bernarda Ferreira de la Cerda (silva III), Ana de Zuazo, María de Zayas (silva VIII). Comenta la lista Simón A. Vosters, «Lope de Vega y las damas doctas", en Actas del Tercer Congreso Internacional de Hispanistas celebrado en México D.F. del 26 al 31 de agosto de 1968, ed. Carlos H. Magis, México, Asociación Internacional de Hispanistas, El Colegio de México, 1970, pp. 909-921, menciones arropadas con la cita de otras mujeres ilustres clásicas sacadas de polianteas, como demuestra en su trabajo "Lope de Vega y Juan Ravisio Textor. Nuevos datos", Actas del Cuarto Congreso Internacional de Hispanistas, celebrado en Salamanca, agosto de 1971, ed. Eugenio de Bustos Tovar, Salamanca, Asociación Internacional de Hispanistas, 1982, pp. 785-790. Véase también el trabajo de Nieves Baranda «Desterradas del Parnaso. Examen de un monte que solo admitió musas» en este mismo número.

4. Para el sentido de la imagen del Monte Parnaso y su metáfora correlativa en estos dos textos clave, véanse, entre otros, los estudios de Ellen Lokos, «El lenguaje emblemático en el Viaje del Parnaso», Cervantes, 9/1 (1989), pp. 63-74; Antonio Carreño, «El Laurel de Apolo de Lope de Vega y otros laureles», BHi, 1(2004), pp. 103-128, y Julio Vélez-Sainz, El Parnaso español: canon, mecenazgo y propaganda en la poesía del Siglo de Oro, Madrid, Visor, 2006.

5. José Manuel Rico, "Algunas consideraciones sobre los procesos de canonización en la preceptiva literaria. Siglo XVII», En torno al canon: aproximaciones y estrategias, pp. 141- 
acercarme a los mecanismos de canonización y de formación del parnaso aragonés femenino; un parnaso en principio local, configurado, en la década de 1640-1650, en torno a la figura del aragonés Juan Francisco Andrés de Uztarroz (1606-1653), erudito, poeta, presidente de la Academia zaragozana de los Anhelantes, historiador, cronista del Reino de Aragón desde 1646, así como autor de medio centenar de obras ${ }^{6}$. Entre ellas figura el Aganipe de los cisnes aragoneses (c. 1652, manuscrito), un poema, compuesto a partir de motivos comunes a las citadas obras de Cervantes y Lope, que resume la historia de la poesía aragonesa del momento y resulta un ejemplo más de las nóminas y relaciones de ingenios ceñidas a espacios cronológicos y geográficos configuradores de los diferentes cánones áureos ${ }^{7}$. El poema recoge la mención de algunas poetas aragonesas y representa en este sentido la oficialización del canon local femenino, el cuadro de familia que pervivirá en la memoria del tiempo con escasas variaciones. Tras la enumeratio de estas mujeres que llegaron hasta la fuente Aganipe del Helicón, se esconde un profundo conocimiento de la poesía femenina y una red de relaciones

166, p. 165. Véase también Lía Schwartz, «Siglos de Oro: cánones, repertorios, catálogos de autores», Insula, 600 (1996), pp. 9-12.

6. Para su vida es indispensable la consulta de la obra de Ricardo del Arco, La erudición española en el siglo XVII y el cronista Andrés de Uztarroz, Madrid, CSIC, 1950, 2 vols. La lista de sus obras, muchas de ellas manuscritas, la confecciona Félix Latassa (1796; 1796-1802), véase Bibliotecas antigua y nueva de escritores aragoneses de Latassa aumentadas y refundidas en forma de diccionario bibliográfico-biográfico por don Miguel Gómez Uriel, Zaragoza, Imprenta de Calisto Arińo, 1884-1886, 3 vols., de la que puede consultarse en la red la edición electrónica a cargo de M.J. Pedraza Gracia, J.A. Sánchez Ibáńez y L. Julve Larraz, 1999. Para su importancia en la historia de la bibliografía aragonesa, véanse los recientes estudios de Alberto Montaner Frutos, «La bibliografía aragonesa: periodización y estudios sobre manuscritos», en Cien años de filología en Aragón. VI Curso sobre lengua y literatura en Aragón, eds. José-Carlos Mainer y José Ma Enguita, Zaragoza, Institución «Fernando el Católico», 2006, pp. 27-99, pp. 37-41, y Genaro Lamarca Langa, «Aragón y sus libros. Fuentes bibliográficas aragonesas en el siglo XX y sus antecedentes», en el mismo volumen, pp. 101-119. En relación con su interés por la poesía, recuérdese que, entre sus obras tempranas, figura la hoy perdida Defensa de la Poesía Española respondiendo a un discurso de don Francisco de Quevedo (1632) donde, presumiblemente, se defendería de los ataques quevedianos contra los cultistas en medio de todo el debate sobre la poesía gongorina.

7. Desde el último tercio del XVI, la multiplicación de estas nóminas es creciente y explica los cambios operados en el concepto de canon, como estudia Pedro Ruiz, «En los inicios del canon lírico», Voz y Letra, XV/1(2004), pp. 25-52, p. 44. Juan Francisco Andrés de Uztarroz, Aganipe de los cisnes aragoneses celebrados en el clarín de la Fama, Zaragoza, Tip. de Comas hermanos, 1890; reprod. facsímil de la edición de Amsterdam, Jordan de Asso, 1781. Puede consultarse también en edición electrónica a cargo de M. J. Pedraza Gracia, J. Á. Sánchez Ibáñez y L. Julve Larraz, Zaragoza, Universidad de Zaragoza, Facultad de Filosofía y Letras, 1999. 
personales y literarias con algunas de ellas que hablan del interés que Andrés de Uztarroz mostró por la escritura femenina como poeta, como crítico y como historiador, una triple y enriquecedora mirada para considerar la (desprestigiada) poesía femenina en un momento en el que no dejaba de ser cuestionada.

\section{Treguas a las almohadillas, tiempo PARA la POEsía}

El incremento de mujeres escritoras y especialmente poetas en la primera mitad del siglo XVII es innegable y, junto al de poetas varones, determina, en palabras del polígrafo Juan Caramuel, la fisonomía del siglo ${ }^{8}$. Este auge de la poesía femenina se pone de manifiesto, por toda la geografía nacional, en la celebración de justas y certámenes poéticos especialmente a partir de 1615, año de la beatificación de Teresa de Jesús, modelo de mujer escritora ${ }^{9}$. Las poetas colaboran también con sus versos en preliminares de libros o en exequias poéticas como las dispuestas a la muerte de Lope de Vega (Fama posthuma a la vida y muerte del doctor frey Lope Félix de Vega y Carpio, Madrid, 1636) y Pérez de Montalbán (Lágrimas panegíricas, Madrid, 1639) ${ }^{10}$; con sus poemas rinden homenaje en este caso a dos autores de renombre cuya laudatio

8. Juan Caramuel de Lobkowitz, Epistolas Familiares, en Primus Calamus (Apud Sanctum Angelum Della Fratta, 1665), editadas y analizadas por Héctor Hernández Nieto, Ideas literarias de Caramuel, Barcelona, PPU, 1992, pp. 185-204. Una selección de las mismas brinda también, junto a otros interesantes textos, A. Porqueras Mayo, La teoría poética en el Manierismo y Barroco españoles, Barcelona, Puvill Libros, 1989, p. 349.

9. La presencia de mujeres en las justas, iniciada en torno a 1600, se consolida en el primer decenio, se mantiene vigorosa hasta 1650 aproximadamente y decae a partir de entonces, según explica Nieves Baranda, «Las mujeres en las justas poéticas madrileñas del siglo XVII», en Figures de femmes. Hommage à Jacqueline Ferreras, ed. Thomas Gomez, Nanterre, Centre de Recherches Ibériques et Ibéro-américaines de l'Université Paris X Nanterre, 2003, pp. 19-41; véase también su trabajo "Reflexiones en torno a una metodología para el estudio de las mujeres escritoras en justas del Siglo de Oro", en Memoria de la palabra. Actas del VI Congreso de la Asociación Internacional Siglo de Oro, I, ed. de M. L. Lobato y F. Domínguez Matito, Madrid, Iberoamericana/Vervuet, 2004, pp. 307-316.

10. La admiración femenina por el Fénix era evidente y así se confirma en su entierro como observa Francisco Ximénez de Urrea en una carta a Andrés de Uztarroz fechada el 1 de septiembre de 1635, al comentar, entre otros pormenores, «ubo muchas mugeres», carta editada por Ricardo del Arco, op. cit., I, pp. 98-99. Repasa la participación femenina en ambos certámenes Enrique di Pastena en su edición de Juan Pérez de Montalbán, Fama póstuma a la vida y muerte del doctor frey Lope Félix de Vega Carpio y elogios panegíricos a la inmortalidad de su nombre, Firenze, Edizioni ETS (Biblioteca di Studi Ispanici, 3), 2001, pp. XXXVII-XXXVIII. En el caso de las exequias poéticas de Lope de Vega, de un total de 150 autores, sólo 13 son mujeres; en el de Pérez de Montalbán, casi cuarenta. La lista completa de participantes en ambas celebraciones la analiza Nieves Baranda, «Las mujeres en las justas poéticas madrileñas del siglo XVII», pp. 31-32. 
panegírica redunda también a la larga en beneficio propio, pues la edición de estas coronas fúnebres sancionaba sus versos dentro del conjunto de poetas a concurso. La proliferación de tantas mujeres poetas despierta, sin embargo, numerosos recelos, máxime en un momento en el que se debate la naturaleza y condición de la poesía y su dignidad y calidad se considera devaluada con tanto poeta practicante y aficionado. Las poetas están lógicamente en el punto de mira, se consideran unas advenedizas, unas aficionadas que dan «treguas a las almohadillas», como dice Amada y Torregrosa en la Palestra numerosa austriaca $(1650)^{11}$, y puntual y ocasionalmente escriben versos. La calidad de los mismos no puede dejar de ser discutida en un momento en el que todavía se siguen cuestionando las facultades intelectuales de las mujeres y su capacidad creadora se considera menor. Sin entrar en el nuevo rumbo que toma la querella de las mujeres, los ejemplos que ilustran el debate son muy diversos. Recuérdense, por un lado, los misóginos y severos juicios de Zabaleta en los Errores celebrados, para quien «la mujer poeta es el animal más imperfecto y más aborrecible de cuantos forman la naturaleza», sin olvidar los de Quevedo ${ }^{12}$, y por otro las defensas de Fernando de Vera y Mendoza en su Panegyrico por la poesía (1627) ${ }^{13}$ o las de Juan Caramuel de Lobkowitz

11. Ioseph Félix de Amada y Torregrosa, Palestra numerosa austriaca, Huesca, Juan Francisco Larumbe, 1650, en la relación del certamen convocado por Luis Abarca de Bolea, segundo Marqués de Torres, para celebrar las bodas de Felipe IV y Mariana de Austria, alude a la concurrencia de féminas: «y hasta las señoras mugeres, permitiendo treguas a las almoadillas, renovaron lo celebrado de las Sibilas, dando que alabar a todos y que invidiar a muchos, desmintiendo este día la poca satisfación de el numen, pues fueron tantas las que con todo acierto se adoptaron hijas de Minerva, que empatavan casi sus versos a los de los varones», fol. 17. Cito por el ejemplar de la BNM, R/35396.

12. El comentario de Zabaleta surge a propósito de la poetisa Erina, celebrada por Propercio y por Ravisio Textor, véanse sus Errores celebrados, Madrid, 1653, error VIII, en A. Porqueras Mayo, op. cit., p. 337. En relación con Francisco de Quevedo, al margen de La culta latiniparla, recuérdese la "Premática del desengaño contra los poetas güeros, chirles y hebenes» incluida en El Buscón, ed. Fernando Cabo Aseguinolaza, Barcelona, Crítica, 1993, libro II, cap. 3, donde da cuenta del contagio de los poetas vanos e insustanciales a las mujeres poetas: «Iten, habiendo considerado que esta seta infernal de hombres condenados a perpetuo conceto, despedazadores del vocablo y volteadores de razones han pegado dicho achaque de poesía a las mujeres, declaramos que nos tenemos por desquitados con este mal que las hemos hecho del que nos hicieron con la manzana», p. 119.

13. Fernando de Vera y Mendoza, Panegyrico por la poesía, Montilla, Manuel de Paiva, 1627, periodo $14^{\circ}$, edición facsímil, Valencia, El ayre de la almena, 1968, hace una alabanza de algunas mujeres que «han escrito en verso con grandíssimo ingenio y erudición, que es cierto aver ecedido a muchos hombres celebrados del siglo», fol. 56 r., defendiendo su capacidad para ello. Salvo el ejemplo modélico de Santa Teresa, empieza a enumerar lugares (Granada, Antequera, Osuna, Sevilla) pero no cita, sin embargo, ningún nombre femenino frente a la extensa lista de poetas masculinos. Como muy bien sugiere Pedro Ruiz, «Una respuesta al 
en su, ya citado, Primus Calamus (1665). En la epístola IV de este libro, Caramuel recrea el debate a través del diálogo entre Federico, que reconoce que en el presente siglo "las heroínas y la vírgenes se deslizan al parnaso, beben las cristalinas aguas del Helicón y cantan poemas a los cadenciosos murmullos de las ondas», y Ausonio, que las censura citando como ejemplo las «insulsas simplezas» de las incluidas en La fama póstuma de Lope de Vega, parejas a las de los poetas barberos ${ }^{14}$. No ajeno al debate de sus personajes, Caramuel sale en defensa de las mujeres poetas recordando que «las musas son mujeres y nada menos que diosas del parnaso", un argumento de género de peso para valorarlas. Su discurso se ve contrarrestado, sin embargo, por el reconocimiento y valoración en las mejores de una "dicción varonil», una manera eufemística de reconocer los logros de una mujer concreta sin atentar contra el axioma según el cual femineidad y creatividad son incompatibles, pues por naturaleza la mujer no es sabia y aquellas que rompen la norma son excepcionales y de espíritu varonil, como recordará también Gracián en El Político $(1640)^{15}$. En general, la poesía femenina no está reconocida en la época y no goza de ningún prestigio, porque, efectivamente, en la mayoría de los casos las poetas son simples y ocasionales versificadoras y entienden la poesía como un ejercicio o un ornato que sirve para el lustre social, como se refleja también en la literatura de la época. Frente a esta opinión generalizada, las que se sienten auténticas poetas, el caso de Feliciana Enríquez de Guzmán, p.e., se rebelan y se enfrentan contra «los poetas cómicos de España» (los ordinarios, según Cervantes en El retablo de las maravillas), en el afán de significarse y distanciarse de ellas y de ellos ${ }^{16}$.

Panegrírico por la poesía. Esbozos de crítica en la Andalucía Barroca», NRFH, 54/2(2006), pp. 453-488, p. 462, probablemente Vera estaba aludiendo a las escritoras incluidas en la Primera parte de las Flores de poetas ilustres de España de Pedro Espinosa, 1605. En cualquier caso, en los planes de Vera y Mendoza estaba escribir sobre «Mugeres capazes de hazer versos», como se lee en la «Resunta deste Panegyrico».

14. «Por lo demás, no carece de injusticia y envidia lo dicho contra los poemas de las mujeres: las musas son mujeres y nada menos que diosas del parnaso; añádase que en este libro hay muchos escritos de damas españolas donde la dicción varonil y la vivacidad y eficacia de los conceptos se elevan por encima del coturno femenino. Tal es la fisonomía de nuestro siglo», Juan Caramuel de Lobkowitz, Epistolas familiares, p. 193.

15. Baltasar Gracián, El Político don Fernando el Católico, prólogo de Aurora Egido, Zaragoza, Institución «Fernando el Católico», 2000, p. 192, para quien «En España han passado siempre plaza de varón las varoniles hembras», p. 195. Calificar la escritura femenina de estilo viril es lo mismo que considerar a la mujer escritora como un personaje no representativo de su sexo, sino único, como explica Laura Freixas, Literatura y mujeres, Barcelona, Destino, 2000, p. 132, y similar a calificarla como «Décima Musa» o "Cuarta Gracia».

16. Así lo muestra Feliciana Enríquez de Guzmán en la "Carta Executoria» que cierra su Tragicomedia de Los jardines y campos sabeos (1624; $16272^{\text {a }}$ ed.), donde los poetas cómicos 


\section{ANDrÉS DE UZTARroZ, JUEZ DEL PARNASO ARAgonéS}

Sin entrar directamente en la polémica, Andrés de Uztarroz toma partido por las escritoras, las anima al estudio y a la creación, dirige y censura sus escritos y, como historiador, las rescata para la historia, para una historia de la escritura femenina que en algún momento, como veremos, quizá estuvo tentado a escribir. Primero lleva a cabo una labor de selección y criba en los certámenes poéticos, mundo que conocía bien porque, como Lope de Vega ${ }^{17}$, había participado como concursante y como organizador ya desde 1634, fecha en la que desde la Academia de los Anhelantes promueve un certamen sobre Santo Dominguito de Val ${ }^{18}$. Posteriormente la Universidad le encomienda, en 1643, el Certamen poético que la Universidad de Zaragoza consagró a D. Pedro de Apaolaza ${ }^{19}$, un año después edita el certamen dedicado a la Virgen de Cogullada (1644) ${ }^{20} \mathrm{y}$ finalmente, en 1646, la ciudad de Zaragoza le

se querellan contra ella «diziendo que siendo muger y no pudiendo hablar entre poetas, avía tenido atrevimiento de componer la dicha Tragicomedia», acusación contra la que se defiende. Analiza esta carta ejecutoria M. Reina Ruiz, Monstruos, mujer y teatro en el Barroco. Feliciana Enríquez de Guzmán, primera dramaturga española, New York, Peter Lang, 2005, pp. 149-171, texto que puede relacionarse también con la anónima respuesta epistolar ( $\mathrm{A}$ Don Panegirista por la Poesía el Fiscal Parnaso, salud») contra la obra de Fernando de Vera y Mendoza antes citada, y con toda la literatura de academias y vejámenes. Se trata, en cualquier caso, de un mecanismo de defensa y autocanonización como los analizados por Pedro Ruiz, "En los inicios del canon lírico áureo», p. 48.

17. Lope de Vega había organizado diferentes justas en Toledo $(1605,1608)$ y Madrid $(1615,1621,1622)$ con participación femenina. Como sugiere Nieves Baranda, «Las mujeres en las justas poéticas madrileñas del siglo XVII», el mismo Lope pudo animar a algunas poetas a participar en estos certámenes "por la novedad reciente de que las mujeres mostraran sus versos en público», p. 23.

18. Desde la Academia de los Anhelantes, en el año 1634, Andrés de Uztarroz (el Solitario) propuso a los académicos una contienda poética sobre el mártir, recordada años después en su Historia de Santo Domingo de Val, Zaragoza, 1643, p. 176 (cito por el ejemplar de la Biblioteca Universitaria de Zaragoza, D-24-115). Edita las composiciones presentadas a la misma, Jaime Suárez, «Mausoleo que la Academia de los Anhelantes erigió en memoria del doctor Baltasar Andrés de Ustarroz», AFA, I (1945), pp. 151-216. No participó ninguna mujer.

19. El certamen poético que la Universidad de Zaragoza consagró a la munificencia y liberalidad del Ilustrísimo y Reverendísimo Señor Arzobispo don Pedro de Apaolaza, 1643, manuscrito. Cito como Apaolaza por la edición de Aurora Egido y Ángel San Vicente, Juan Francisco Andrés de Uztarroz. Certamen poético que la Universidad de Zaragoza consagró al arzobispo D. Pedro de Apaolaza en 1642 según el manuscrito E. 41-5.943 de la Biblioteca Rodríguez-Moñino/Brey, Zaragoza, Institución «Fernando el Católico», 1986. A la llamada acuden en este caso: Teresa Pérez de Oliván, Catalina Albalate, Mariana de Mur, Juana Sánchez y Acuña, María Francés, Tomasina Calvo, Isabel Ramón, María Pérez de Oliván y Justa de Silves Ricarte.

20. Certamen poético de Nuestra Señora de Cogullada, ilustrado con una breve chronología de las imágines aparecidas de la Virgen Sacratíssima en el reino de Aragón, Zaragoza, Hospital 
encarga la Contienda poética que la Imperial Ciudad de Çaragoça propuso a los ingenios españoles en el fallecimiento del Serenissimo señor don Balthasar Carlos de Austria ${ }^{21}$, certámenes a los que acudieron, como en otras ocasiones ${ }^{22}$, numerosas mujeres, religiosas o laicas, pertenecientes en general a la nobleza local, y unas perfectas desconocidas fuera de los círculos aragoneses ${ }^{23}$. En

de Nuestra Señora de Gracia, 1644. Cito como Cogullada por el ejemplar de la Biblioteca Universitaria de Zaragoza, D-83-140. En este certamen, en el que Uztarroz actúa como juez, participan numerosas mujeres: Isabel Alberta García, Vincencia de Mendoza, Leonor de Villalpando y Latrás, Agustina de Beragua, Bernarda Remírez, Isabel del Mas, María de Zaldívar y Albaina, María Ana López, Josefa Valentina de Colomina y Lascorz, Lorenza Pérez de Bordalva, Eugenia de Castro-Blanco, Petronila de Artrabia y Bolea, Jacinta de Artrabia y Bolea y Josefa Colomina.

21. Contienda poética que la imperial ciudad de Zaragoza propuso a los ingenios españoles en el fallecimiento del Serenissimo Señor don Balthasar Carlos de Austria, Principe de las Españas, Zaragoza, Diego Dormer, 1646. Cito como Baltasar Carlos por el ejemplar de la Biblioteca Nacional, DG micro/7182. Lloran la muerte del príncipe las siguientes poetas: Gerónima de Viu, Sor Gerónima Maicas, María Francés, Josepha Arañón, Tomasina Francés, Sor Gracia Antonia Vagués, Ana de Bolea, Beatriz Jiménez Cerdán, Ana Francisca Abarca de Bolea y Mur, Francisca de Lanaja y Francés, Isabel Sanz de Latrás y Camargo y Sor Jusepa Comis de Uberte.

22. Sin hacer un vaciado exhaustivo, figuran mujeres, p.e., en las siguientes obras: Relación de las exequias que hizo la Imperial Ciudad de Zaragoza a la muerte de la serenissima Reyna Margarita de Austria nuestra señora. Con el Certamen que su Universidad propuso de versos y jeroglificos (Zaragoza, 1612); Francisco de Diego Ainsa y de Iriarte, Translación de las reliquias del Glorioso Pontifice S. Orencio (Huesca, 1612); Luis Díez de Aux, Retrato de las Fiestas de beatificación de Teresa de Jesús (Zaragoza, 1615); Pedro Martín, Certamen poético a las fiestas de la translación de la reliquia de San Ramón Nonat (Zaragoza, 1618); La justa poética en defensa de la pureça de la Inmaculada Concepción de la Virgen Santíssima mantenida y premiada por don Sancho Çapata (celebrada en Calatayud en 1618); Compendio de las fiestas que ha celebrado la Imperial Ciudad de Çaragoça [...] al Ilustríssimo Señor Don Fray Luis Aliaga (Zaragoza, 1619); Felices de Cáceres, El caballero de Ávila (Zaragoza, 1623) y Felices de Cáceres, Justa poética por la Virgen Santíssima del Pilar (Zaragoza, 1629).

23. Un primer acercamiento a estas justas brinda José María Castro y Calvo, Justas poéticas aragonesas del siglo XVII, Zaragoza, Universidad de Zaragoza, 1937. Para el tema son imprescindibles los estudios de Aurora Egido, «Los modelos en las justas poéticas aragonesas del siglo XVII», RFE, 60(1978-1980), pp. 159-172; "Certámenes poéticos y arte efímero en la Universidad de Zaragoza», en Cinco estudios humanisticos para la Universidad de Zaragoza en su centenario IV, Zaragoza, Caja de Ahorros de la Inmaculada, 1983, pp. 9-78; "Justas poéticas marianas en el Barroco aragonés», en María, fiel al espíritu. Su iconografía en Aragón de la Edad Media al Barroco, Zaragoza, Museo Camón Aznar, 1998, pp. 63-75; Aurora Egido y Luis Sánchez Laílla, "Certámenes literarios aragoneses del Siglo de Oro», en Fiestas Públicas en Aragón en la Edad Moderna, Zaragoza, Centro de Documentación Bibliográfica Aragonesa, 1995, pp. 69-83. Junto con Madrid, Zaragoza es la ciudad española que cuenta con mayor número de participación femenina en estos certámenes, como constata Nieves Baranda, «Las mujeres en las justas poéticas madrileñas del siglo XVII», p. 20. 
los tres casos, Andrés de Uztarroz escribe la relación del certamen con la metáfora parnasiana ${ }^{24} \mathrm{y}$, gracias a ella, las poetas viajan también al monte Parnaso, se codean con las musas y reciben críticas y premios, no sólo los cortesanos y olorosos guantes de ámbar o de flores, signo de lujo y distinción ajustado a un concepto de la poesía más cortesana, sino también laureles de la mano del mismo Apolo ${ }^{25}$. En las sentencias, donde enjuicia y valora sus versos con un tono no exento de humor, propio de su estilo, se encierra una incipiente crítica que, vista en conjunto y sumada a la de otros certámenes, ayudará también a medir el alcance de esta poesía femenina.

El discreto Andrés de Uztarroz alaba en general la invención aguda e ingeniosa de muchas mujeres, si bien critica en ocasiones la falta de arte, de técnica, esa que, como dice María de Zayas en el prólogo de sus Novelas amorosas y ejemplares, sólo se consigue con libros y preceptores y no con el cambray en las almohadillas y los dibujos en el bastidor. Es el caso, p.e., de doña Teresa Oliván, a la que se le niegan premios

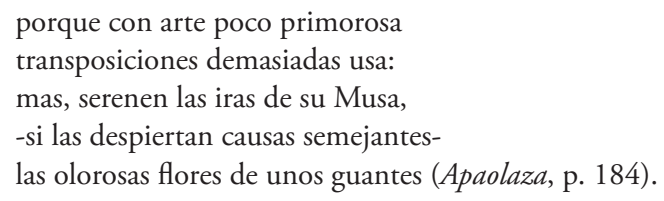

Si a Doña Juana de Sánchez y Acuña «por parecer algo llanas / sus rimas no se han premiado; / Apolo tendrá cuidado / de sus prendas soberanas» (Apaolaza, p. 193), a Isabel Sanz de Armora sólo se le conceden guantes por el «esdrújulo defecto» de sus versos (Baltasar Carlos, p. 102). En otros casos es la falta de adecuación al tema propuesto la que les niega los premios, como le sucede a Ana Vincencia de Mendoza en el primer asunto del certamen de Cogullada:

\footnotetext{
Doña Ana Vicencia de Mendoza, por quien Apolo nuevas glorias goza, si al certamen sus versos ajustara, no dude que las sienes coronara;
}

24. Sobre la misma, véase Luis Vélez-Sainz, El parnaso español: canon, mecenazgo y propaganda en la poesía del Siglo de Oro, cap. 1, pp. 29-60. En el ámbito aragonés ya la había empleado, p.e., Luis Díez de Aux en el Retrato de las fiestas a la beatificación de la bienaventurada Virgen y Madre Santa Teresa de Jesús (Zaragoza, 1615), en el comentario de las sentencias.

25. De ellos habla, como signo cortesano, Baltasar Gracián en El Criticón (Tercera parte, crisi 10). Para su confección, véase María de los Ángeles Pérez Samper, «Los recetarios de mujeres y para mujeres. Sobre la conservación y transmisión de los saberes domésticos en la época moderna», Cuadernos de Historia Moderna, 19 (1997), pp. 121-154, p. 148. 
mas sus doctos retóricos colores merecen guantes de olorosas flores (p. 188).

La monja oscense se alzará con el premio de la contienda en el asunto cuarto, tras presentar un soneto que merece los elogios de Andrés de Uztarroz:

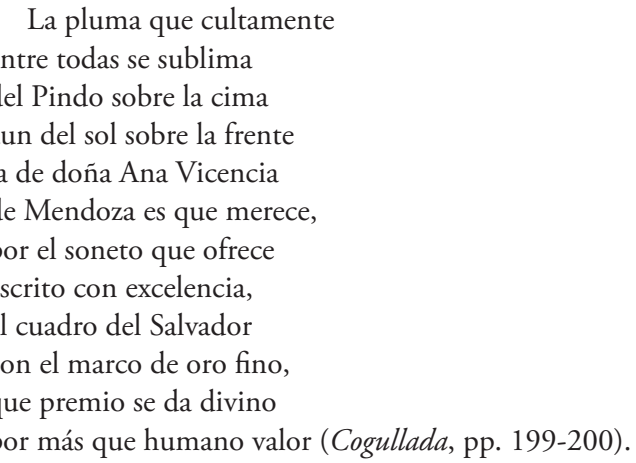

Premio que recordará Gracián al incluir su «ingenioso» soneto («Éste que acaso incierto es al cuidado») como ejemplo "De las ponderaciones de contrariedad» en el discurso VIII de la Agudeza y arte de ingenio (1648), comparando en su caso a la monja poeta con la musa Euterpe. En la Contienda poética en el fallecimiento de Baltasar Carlos, doña Ana Francisca de Bolea

Abarca y Mur desea

del cielo el premio, que el de nuestra mano

le ha parecido vano.

Con los versos del último terceto,

su segundo soneto

prémielo de su mano el mismo Christo,

Dándole la corona de su gloria,

pues de su pluma quiere por victoria;

en el primero solamente guantes

que estarán en sus manos más fragantes (p. 113).

En este caso, a la monja de Casbas le arrebató el protagonismo del certamen Tomasina Francés, prima de Uztarroz y, en palabras del cronista,

La Musa más ladina

es Doña Thomasina

Francés, que de su ingenio y bella mano

Apolo soberano

se enamora y admira 
cuando atento la mira

cómo discurre con su proprio passo

por las floridas cumbres del Parnaso (Baltasar Carlos, p. 111).

Para juzgar el último asunto de esta contienda poética, el mismo Apolo bajará hasta el Tribunal del certamen en el Teatro de la Universidad de Zaragoza y otorgará personalmente el tercer premio a Tomasina Francés por saber escribir culta poesía:

En un piélago de luzes,

el sacro Apolo bañado

llegó al Consistorio nuestro

por la techumbre del claustro.

$Y$ en el trono de una nube

gravemente colocado,

en estas vozes rompió

del pecho el aliento sacro $[\ldots]$

$Y$ porque esse papel ha ennoblecido

esta contienda ilustre, numerosa,

aviendo escrito en él la mano hermosa

de Doña Thomasina

Francés, ninfa del Ebro peregrina,

conceptos proprios, porque no permite

que con otros su ingenio se acredite,

y pues por gloria de sus gracias sumas

buela su ingenio con sus proprias plumas

y esse papel es suyo,

quererle abrir que es delito arguyo,

que examinar sus versos sazonados

que se deven premiar a ojos cerrados,

en tal caso sería

más que equidad, culpable grosería.

Y assí yo solo soy por cuya mano

su frente el laurel ciñe soberano (Baltasar Carlos, pp. 127-130).

Pese a las faltas y yerros de estas poetas, en la mayoría de los casos se las acaba premiando con los guantes de rigor, pues su condición de mujer triunfa sobre la de poeta, merece un respeto («y no solo por ser dama / sus poemas celebramos / si bien cierra este respeto / del más crítico los labios», Cogullada, a propósito de Isabel del Mas, p. 212) y parece exigirla la cortesía («Pero a negarle a una dama / guantes no nos atrevemos, / aunque nos diesse un romance / de mil esdrújulos lleno", Baltasar Carlos, sentencia sobre Isabel Sanz de Armora, p. 102), algo que evidentemente no sucede con los poetas pues, aunque compartan un mismo espacio oral y textual, el trato es diferenciado. 
Como se comprobará, pocos son los nombres de mujeres que se repiten en estos tres certámenes, lo que confirma que en general se trata de poetas ocasionales, mujeres lectoras y aficionadas a la poesía, capaces de escribir versos de tono panegírico ajustándose a los modelos (Garcilaso, Boscán, Petrarca, Argensola), asuntos y normas del certamen, requisitos que, si bien limitan su capacidad creadora, les dan opción a la visibilidad. Las tres relaciones de estas justas, dos impresas y una manuscrita, se convierten, en cualquier caso, en «antologías circunstanciales» que, con su selección y canonización basada en los premios otorgados por los jueces ${ }^{26}$, dan cuenta de una moda social extendida entre las mujeres, rescatan del olvido a estas desconocidas hijas de Minerva y ayudan a prestigiar incluso a las de más renombre, en este caso a Ana Vincencia de Mendoza, Tomasina Francés y Ana Francisca Abarca de Bolea, las únicas que conseguirán finalmente una plaza en el Aganipe de los cisnes aragoneses. Frente a María de Zayas, Ana Caro, Bernarda Ferreira de la Cerda, las aragonesas aprecian este tipo de contiendas poéticas al estar organizadas por el círculo culto en el que se integran, en este caso el lastanosino con Uztarroz al frente ${ }^{27}$. Su participación es una forma de reforzar los vínculos interpersonales, de manifestar su adhesión a un grupo literario y de poder que acaba legitimándolas; la lectura pública de sus versos en el trascoro de la Iglesia Metropolitana de Zaragoza (Cogullada) o en el teatro-paraninfo de la Universidad de Zaragoza (Apaolaza, Baltasar Carlos), así como la impresión del certamen, les confiere la fama, una fama puntual que a veces, sin embargo, cruza fronteras, pues estos libros se difundieron también por tierras italianas ${ }^{28}$.

26. Comenta el valor de estas «antologías», José María Pozuelo Yvancos, "Canon: ¿estética o pedagogía?», Insula, 600 (1996), pp. 3-4, p. 4. Para el alcance de esta poesía, véase Aurora Egido, "Poesía de justas y academias», en Fronteras de la poesía en el Barroco, Barcelona, Crítica, 1990, pp. 115-137.

27. Lo habitual es que acudan mujeres próximas al círculo de los organizadores. Así, p.e., en el Certamen por la traslación de la reliquia de San Ramón Nonat (Zaragoza, 1618), sus participantes, entre ellos muchas mujeres religiosas y nobles, son allegados a los Condes de Aranda organizadores de la convocatoria, como explica Aurora Egido, "La Nobleza virtuosa de la Condesa de Aranda, doña Luisa de Padilla, amiga de Gracián", AFA, LIV-LV(1998), pp. 9-41, p. 13. Lo mismo sucede con la Palestra Numerosa Austriaca (Huesca, 1650), en la que varios participantes son naturales de Corella, quizá porque este enclave navarro pertenecía a los dominios del marqués de Torres, según comenta José Miguel Oltra Tomás, «Un mundo para un certamen: aproximación a la Palestra Numerosa Austriaca de Huesca (1650)», en La cultura del Barroco. Los jardines: arquitectura, simbolismo y literatura, ed. José Enrique Laplana Gil, Huesca, Instituto de Estudios Altoaragoneses, 2000, pp. 93-110, p. 109.

28. En una carta de Fr. Jerónimo de San José a su amigo Andrés de Uztarroz, le comunica haber enviado un ejemplar del Certamen poético de Cogullada a Nápoles a la vista de la buena acogida que habían alcanzado otras obras suyas. Recoge el dato Ricardo del Arco, op. cit., 
ANDrÉS DE UZTARroZ, MECENAS DE ESCRITORAs. EPISTOLARio

En múltiples ocasiones, la participación en estas justas es el único testimonio que perdura de muchas de estas poetas. Frente a Ana Francisca Abarca de Bolea, autora de las Catorce Vidas de la orden del Cister (1655) y de la Vigilia y Octavario de San Juan Bautista (1679), de Tomasina Francés no se conoce otra obra que los versos presentados al certamen por la muerte del príncipe Baltasar Carlos y ellos son, junto al parentesco que la une a Uztarroz, los que le aseguran el puesto en el Aganipe de los cisnes aragoneses. Su relación con el cronista, confirmada por las cartas familiares conservadas ${ }^{29}$, le sirvió sin duda alguna para darse a conocer y para introducirse en el citado círculo lastanosino, donde se relacionaría con todo el grupo, incluido Baltasar Gracián, cuyos versos pide en una de sus cartas a Andrés de Uztarroz, y Juan de Moncayo, que la cita elogiosamente en la Fábula de Atalanta e Hipomenes (Zaragoza, 1652) ${ }^{30}$. Nada más se sabe de su quehacer literario.

Las cartas «literarias» cruzadas con la burgalesa Luisa de Padilla, más conocida como la Condesa de Aranda, con la madrileña María Nieto y con Ana Francisca Abarca de Bolea, además de trazar una curiosa red de relaciones, desvelan interesantes datos para entender la compleja peregrinación femenina al Parnaso, para comprender las estrategias empleadas por las autoras en el intento de darse a conocer, de legitirmarse y de hacerse un sitio en la república de las letras. Juan Francisco Andrés de Uztarroz, que mantenía una estrecha relación con los Condes de Aranda, tomó a Luisa de Padilla (1590-1646) como interlocutora y confidente de sus trabajos. Interesada por la educación nobiliaria y por la historia, como demuestran sus obras, Andrés

I, p. 357. El epistolario de Jerónimo de San José lo edita José Manuel Blecua, «Cartas de Fray Gerónimo de San José al cronista Juan Francisco Andrés de Uztarroz», AFA, I(1945), pp. 33-150.

29. Cartas de hombres eruditos a Andrés Uztarroz, Madrid, Biblioteca Nacional, Ms. 8.390, fols. 603r, 604 r. En este volumen que reúne el epistolario de Andrés de Uztarroz, las cartas intercambiadas con mujeres aparecen todas juntas: María Nieto, María Guasso y de los Benedettes, Ana Francisca Abarca de Bolea, Teresa Bartolomé, Sor Laurencia Tomás y Tomasina Francés. Dan noticia de las cartas de Tomasina Francés, Manuel Serrano y Sanz, Apuntes para una biblioteca de escritoras españolas desde el año 1401 al 1833, I, Madrid, 1903, Establecimiento Tipolitográfico «Sucesores de Rivadeneyra», 1903, Madrid, Atlas, BAE, 1975, p. 417, y Ricardo del Arco, op. cit., I, p. 357.

30. Juan de Moncayo, Fábula de Atalanta e Hipomenes, Zaragoza, 1652. Cito por ejemplar de la Biblioteca Universitaria de Zaragoza D-24-99, al que le faltan los preliminares. La obra va precedida de once o doce poemas laudatorios de firma femenina y en la fábula recoge largas listas de nobles mujeres aragonesas con numerosos elogios. Cita a Tomasina Francés en los cantos cuarto (octava 5, p. 114) y séptimo (octava 131, p. 129), en este caso como «corriente sonora del Pindo», «flor del Parnaso» y «perla de Elicona». 
de Uztarroz le daba cuenta en sus cartas de sus hallazgos y descubrimientos, de sus investigaciones históricas y de sus proyectos literarios. En una de estas epístolas (fechada el 10 de marzo de 1642 ), la condesa de Aranda demuestra su interés por la arqueología y le promete la confidencialidad más absoluta en torno al curso de sus investigaciones, porque, dice, «sé muy bien lo que se siente ver que se honrren otros con lo que ha costado mucho trauajo, y los hijos de ingenio se aman mucho» ${ }^{31}$. En sus palabras se escapa la queja resentida de una autora que se lamenta quizá de su propia experiencia, de haber tenido que publicar su obra a nombre de un autor obligada por su propia condición de mujer noble y por los formalismos sociales, que no verían con buenos ojos que una dama de linaje como ella se ocupara de tales menesteres. No hay que olvidar que en 1642, fecha de la carta, ya había publicado tres partes de la Nobleza Virtuosa (1637-1639) y los Elogios de la verdad e invectiva contra la mentira (1640) a nombre del agustino Fray Pedro Enrique Pastor ${ }^{32}$. Su orgullo de autora le lleva a reivindicar en estos renglones lo propio y a firmar sin miramientos las obras restantes, primer paso para vencer ese miedo de que sus obras se vulgarizaran con la imprenta apuntado por Baltasar Gracián en El Discreto ${ }^{33}$. Aunque en este caso no nos consta que tuviera a Uztarroz como mentor, está claro que su amistad con Gracián pudo llevarle a discutir pormenores de su obra y a intercambiar con él cartapacios y materiales, según sugiere Aurora Egido ${ }^{34}$.

31. Manuel Serrano y Sanz, op. cit., II, p. 103.

32. Aurora Egido, «La Nobleza virtuosa de la Condesa de Aranda, doña Luisa de Padilla, amiga de Gracián", pp. 9-41. Le seguirán las Excelencias de la castidad (1642) y la Idea de Nobles y sus desempeños en aforismos: Parte Quarta de Nobleza virtuosa (1644) rematada por la Vida del Marqués de Santillana, obras recientemente estudiadas por Nieves Baranda, «Escritos para la educación de nobles en los siglos XVI y XVII», BHi, 97(1995), pp. 157-171; Aurora Egido, «La Idea de Nobles de la Condesa de Aranda y Baltasar Gracián», en El Conde de Aranda y su tiempo, eds. José A. Ferrer Benimeli, Esteban Sarasa y Eliseo Serrano, Zaragoza, Institución "Fernando el Católico», 2000, pp. 63-80; «La Vida del Marqués de Santillana de doña Luisa de Padilla, Condesa de Aranda», en Silva. Studia philologica in honorem Isaías Lerner, eds. Isabel Lozano-Renieblas y Juan Carlos Mercado, Madrid, Castalia, 2001, pp. 213-226; y Luciana Gentilli, «La Nobleza Virtuosa della Condesa de Aranda: il ritratto della 'Gran señora perfecta'”, Annali della Facoltà di lettere e filosofia [Università di Macerata], XXXVII (2004), pp. 199-221; «A proposito dei 'consejos' della Condesa de Aranda», en Donne di palazzo nelle corti europee. Tracce e forme di potere dall'età moderna, ed. Angela Giallongo, Milano, Edizioni Unicopli, 2005, pp. 121-130.

33. Baltasar Gracián, El Discreto, ed. Aurora Egido, Madrid, Alianza, 1997, p. 158.

34. Aurora Egido, «La Idea de Nobles de la Condesa de Aranda y Baltasar Gracián», p. 72. Aunque a ella se dedica el Certamen a San Ramón Nonat, no consta que escribiera poesía. En sus Elogios de la Verdad condena el mal uso de la poesía y expulsa a los poetas profanos de la ciudad de la Verdad. 
Poco tiempo después, Andrés de Uztarroz mantiene también una fluida correspondencia epistolar con la madrileńa María Nieto y con Ana Francisca Abarca de Bolea, monja del monasterio cisterciense de Casbas (Huesca), convirtiéndose para ambas en su mecenas, consejero y censor literario. Si bien no sabemos exactamente cuándo y cómo surge la relación con la madrileña, lo cierto es que sus primeros versos (quizá Lágrimas a la muerte de Isabel de Borbón, 1645) llegaron hasta sus manos. El cronista los elogió generosamente y ella se lo agradeció nombrándolo su mecenas ( «En las ocasiones que se ofrescan sienpre tendre a vmd. por mi Mecenas», carta de 1645), remitiéndole desde entonces sus poemas (el Epitalamio y el hoy perdido Templo de la eternidad) antes de darlos a la imprenta («mas primero los vera v.m. para que con su censura no tenga después que temer», carta de 1650) ${ }^{35}$. Como hicieran Góngora, Baltasar Gracián, Bocángel o Juan de Moncayo, la madrileña busca también una primera confrontación de su obra con la "crítica» de un lector selecto, reconocido como autoridad que prestigia y legitima el libro y coadyuvante, en última instancia, de su canonización individual.

Los versos de María Nieto asombraron tanto a Andrés de Uztarroz que los remitió a Lastanosa, "cavallero de mui buenas noticias», para que éste a su vez los enviara a Filhol con el fin de incluir en «el volumen que escrive de mugeres ilustres en letras su nombre de vm.» ${ }^{36}$. En esta carta de 1645, el cronista le informa de este interesante proyecto planeado por Francisco Filhol, noble y erudito francés que mantenía una estrecha relación con Lastanosa, Gracián, Antonio y Francisco Jiménez de Urrea y con Luisa de Padilla, con la que también se carteaba ${ }^{37}$. Andrés de Uztarroz conocía bien las aficiones e inquietudes del eclesiástico de Toulouse pues un año antes, en 1644, había descrito su biblioteca-museo, Diseño de la insigne y copiosa biblioteca de Francisco Filhol, trabajo del que envía un ejemplar a María Nieto para que se haga una idea de la calidad del personaje y de la empresa. Como dice Andrés de Uztarroz, Filhol tenía proyectado crear «un volumen de mujeres ilustres en letras», un repertorio no ya de mujeres sabias, sino de

35. Ricardo del Arco, op. cit., vol I, p. 374, carta de 1645; vol. II, p. 652, carta de 1650.

36. Ricardo del Arco, op. cit., I, p. 346. En el apéndice VII de este estudio se recoge el Diseño de la insigne i copiosa Bibliotheca de Francisco Filhol compuesto por Uztarroz, pp. 981999. En este gabinete de curiosidades encaja bien el proyecto de un «volumen de mujeres ilustres en las letras», del que, por otro lado, no he encontrado más noticias que las de esta carta.

37. Ha apuntado las estrechas relaciones entre estos aragoneses Aurora Egido en Las caras de la Prudencia y Baltasar Gracián, Madrid, Castalia, 2000, caps. IV y V, pp. 117-189, con importantes consideraciones sobre Andrés de Uztarroz, la historiografía aragonesa y el relieve de algunas mujeres dentro de dichos círculos. 
mujeres destacadas en las letras (incluidas las escritoras), quizá en la línea del Teatro delle donne letterate de Francesco Agostino della Chiesa, obispo de Saluzzo, considerado a su vez un precedente del apéndice bibliográfico de Nicolás Antonio, Gynaeceum Hispanae Minervae ${ }^{38}$. Cabe pensar que en dicho plan tendrían cabida también Luisa de Padilla y el resto de escritoras relacionadas con el círculo lastonosino, Ana Vincencia de Mendoza, Ana Francisca Abarca de Bolea y Tomasina Francés. Lejos de encastillarse en localismos, Uztarroz quiere que la fama de la madrileńa se extienda más allá de nuestras fronteras («deseo de que su fama de vm. se dilatara en todas partes», carta de 1645) y actúa de intermediario, sin renunciar, sin embargo, a hacerse de nuevo con los elogiados versos («Por esta ocasion he quedado defraudado de tales obras, pero vm. no permitira que carezcamos dellas», carta de 1645). Esta función mediadora no será la última pues, al tanto de su conocimiento e interés por la poesía femenina, desde Huesca, y por carta fechada en 1647, Baltasar Gracián pide al cronista versos de Tomasina Francés para incorporarlos a la Agudeza y Arte de ingenio que aparecerá en Huesca al año siguiente, en 1648: "y si vm. puede sacar alguna cosa buena y heroyca de la prima Thomasina me olgaría de mostrar la estimacion que tengo y debo» ${ }^{39}$. El envío de Andrés de Uztarroz se sumará a la cita de otras poetas quizá conocidas también a través suyo, pues, como dice en la misma epístola, "Doña Ana ya está campanudamente, la de aqui; y la de Casvas estara tambien. Dońa María Nieto ya va con repique, etc. Vm. saque lo que le suplico». Versos femeninos todos ellos que pensaba unir a los de Luciana de Narváez e Hipólita de Narváez, poetas que se han venido relacionando con el círculo antequerano y recogidas por Pedro Espinosa en las Flores de

38. Ambas responden «al deseo de catalogación que acompaña al individualismo renacentista y a la nueva idea de 'estilo' a la vez que representa el punto de partida historiográfico de una posible historia literaria de la escritura femenina», en palabras de Lola Luna, "Las escritoras en la Bibliotheca de Nicolás Antonio", en Leyendo como una mujer la imagen de la mujer, Barcelona, Anthropos, 1996, pp. 28-40, p. 33. En cualquier caso, estas obras llevan a cabo una segregación que quiere poner de manifiesto la existencia de escritoras dándoles un espacio propio.

39. La carta la reproduce Ricardo del Arco, op. cit., I, p. 492, quien identifica a dońa Ana «la de aquí» con Ana Paciencia Ruiz de Urríes y Castillo, p. 495, poeta oscense participante en la Palestra numerosa austriaca. Creo, sin embargo, que se trata de la también oscense y ya mencionada dońa Ana Vincencia de Mendoza, porque es la que finalmente aparece citada en la Agudeza y arte de ingenio, en Baltasar Gracián, Obras completas, introd. Aurora Egido, ed. Luis Sánchez Laílla, Madrid, Espasa-Calpe, 2001, Discurso VIII, «De las ponderaciones de contrariedad»: «Vese en este ingenioso soneto, con razón premiado en Zaragoza, y discurrido en Huesca por dońa Ana Vincencia de Mendoza, a la milagrosa imagen de la Reina de los cielos", p. 380. El soneto, como antes se ha comentado, fue premiado en el Certamen poético de Nuestra Señora de Cogullada (1643). 
poetas ilustres (Valladolid, 1605), antología de la que el jesuita tomó más de una treintena de composiciones como ejemplos de agudeza y uno de los pocos repertorios en los que podía hallar muestras de poesía femenina, quizá por imitación de los modelos italianos ${ }^{40}$. De todo el material demandado y acopiado, finalmente Gracián acaba citando, además del poema de Ana Vincencia de Mendoza, otro de Ana Francisca Abarca de Bolea «y no el menos conceptuoso de sus muchos y elegantes poemas", concretamente "Víspera de aquel muy hombre», incluido en el discurso XXXI como ejemplo «De la Agudeza nominal» (p. 586). Por entonces, Ana Francisca Abarca de Bolea no había entregado todavía nada a la imprenta, de manera que Gracián se convierte en su primer y expreso mentor a la hora de darla a conocer públicamente ${ }^{41}$. El jesuita recoge también un soneto de María Nieto (discurso XVII, «De las ingeniosas transposiciones», p. 449) a la memoria de la reina Isabel de Borbón, un soneto ("Cede al sueño fatal la que divina", pp. 451-452) en este caso publicado ya en varias ocasiones ${ }^{42}$. Los versos de la prima Tomasina se quedaron por el camino. La decisión de Gracián

40. Pedro Espinosa, Flores de poetas ilustres, ed. Belén Molina, Fundación José Manuel Lara, 2005, p. XXI. La antología incluye, además de las dos citadas, unos versos de Cristobalina Fernández de Alarcón, quizá sin más pretensión que la de imitar los modelos italianos, abiertos a la poesía femenina, como bien sugiere Belén Molina, La trama del ramillete. Construcción y sentido de las "Flores de poetas ilustres» de Pedro Espinosa, Sevilla, Fundación José Manuel Lara, 2003, p. 201. Su inclusión sería, en cualquier caso, una muestra más de esa clara y renovadora propuesta de modelo poético que encierra la antología de Pedro Espinosa, como estudia Pedro Ruiz, "Renovación del orden genérico: las Flores de poetas ilustres (1605)», Caliope. Journal of the Society for the Renaissance and Baroque Hispanic Poetry, 9/1(2003), pp. 5-33. Sin embargo, ninguna de estas poetas figurará en la colección de Poesias varias de grandes ingenios españoles (1654) de Josef Alfay, en la que la mitad de poetas incluidos se registran ya en la Agudeza y arte de ingenio y sobre la que planea la sombra de Gracián, según sugiere José Manuel Blecua en su edición Poesías varias de grandes ingenios españoles recogidas por Josef Alfay, Zaragoza, Institución «Fernando el Católico», 1946, p. XI, y M. Romera-Navarro, «La antología de Alfay y Baltasar Gracián», Hispanic Review, XV(1947), pp. 325-345.

41. Baltasar Gracián, Agudeza y arte de ingenio, ed. cit., pp. 396-370.

42. El soneto de María Nieto "Cede al sueño fatal la que divina» comentado por Gracián en la Agudeza y arte de ingenio, ed. cit., pp. 451-452, aparece por primera vez publicado como cierre de El cristal más puro representando imágenes de divina y humana politica, para exemplo de principes, labrado de las acciones heroicas de doña Isabel de Borbón de Joseph Micheli y Márquez (Zaragoza, 1644), fol. 22 v; con él concurre también a la Pompa funeral, honras y exequias en la muerte de la muy alta y católica señora doña Isabel de Borbón (Madrid, 1644), fol. 100 r, y se repite en el anónimo Prodigio lastimoso y fúnebre a la más celebrada princesa D. Isabel de Borbón (Zaragoza, 1644), fol. 22 v. Finalmente, María Nieto lo incluye en las Lágrimas a la muerte de Isabel de Borbón (Madrid, 1645), fol. $1 \mathrm{v}$. 
de ilustrar la agudeza y arte de ingenio con ejemplos femeninos resulta un espaldarazo definitivo para el reconocimiento de estas autoras y en general para el de la escritura femenina.

En su labor de mediación, Andrés de Uztarroz pone en relación a María Nieto con los miembros del círculo lastanosino y éstos la tendrán en cuenta. Así el Marqués de Torres la invitará personalmente por carta a participar en la Palestra numerosa austriaca oscense (Huesca, 1650) ${ }^{43}$; por entonces María Nieto era ya una escritora de corte, especializada en el género panegírico y con dos obras publicadas: las Lágrimas a la muerte de Isabel de Borbón, (1645) y el Epitalamio a las bodas de Felipe IV y Mariana de Austria (1649). La madrileńa acude a la llamada de este certamen de exaltación monárquica y patriótica por amistad, pero también porque es un buen escaparate para reforzar su imagen de escritora especializada en la historia de la monarquía. Por "mandato" ("y si no fuera por obedecer no tomara la pluma»), con la premura de tiempo y falta de inspiración, pues «las Musas andan muchas vezes fuera de casa, y no ay darles alcance», según dice en una carta fechada el 20 de enero ${ }^{44}$, en dos días María Nieto compone el soneto «Qual lienzo en que animó pinzel valiente» que remite a Andrés de Uztarroz para que éste, una vez más, haga de intermediario y se lo envíe a Lastanosa y al Marqués de Torres "para que entre en juicio» en el segundo asunto del certamen, el referido al enamoramiento de Felipe IV a través de un camafeo. Junto a los versos, anuncia el envío de una nueva obra suya, Templo de eternidad, hoy perdida, para que el mentor la juzgue antes de darla a la imprenta. La confianza que María Nieto tenía en los versos remitidos al concurso («que si no me engaña el amor propio es del asunpto con decencia») se confirma y la madrileña se alza con el premio de una Virgen del Pilar de oro.

Al llamamiento de la Palestra acude también, además del poeta Andrés de Uztarroz, Ana Francisca Abarca de Bolea, tía del Marqués de Torres, el organizador del certamen, sin obra todavía impresa y en este caso participante con unas octavas sobre la Inmaculada Concepción (séptimo asunto). Ana Francisca Abarca obtiene el segundo premio, un libro de Horas de Nuestra Señora, y los elogios del licenciado Amada y Torregrosa, autor de la relación del certamen, que acaba nombrándola «décima musa de Apolo». La gastada metáfora parnasiana ${ }^{45}$, aplicada a las ilustres, no sirve para calmar el enfado

43. Ricardo del Arco, op. cit., II, p. 652. Para el estudio del certamen, véase el trabajo, ya citado, de José Miguel Oltra Tomás, «Un mundo para un certamen: aproximación a la Palestra Numerosa Austriaca de Huesca (1650)». El licenciado Amada y Torregrosa, emplea la metáfora parnasiana y contrae claras deudas con el poema cervantino.

44. Ricardo del Arco, op. cit., II, p. 652.

45. Con este rango honró Platón a la poeta griega Safo en el Epigrama 6: «Dicen algunos 
de la monja por no obtener el primer premio, otorgado a Juan Nadal, y así lo expresará muchos años después, en 1679, al incluir las mencionadas octavas en la Vigilia y Octavario y con ellas el viejo resquemor de la injusticia vivida ${ }^{46}$. La valía y el orgullo de la escritora convencida no se conforma con estas cortesías, sino con los actos, con el reconomiento expreso y público de campeona absoluta.

A través de las cartas con su mentor, se puede apreciar el crecimiento de estas mujeres como escritoras, el afianzamiento de su conciencia autorial, pero también el alcance de los juicios y críticas del consejero. En una epístola de agradecimiento por la aprobación literaria de su Epitalamio a las felicíssimas bodas del rey nuestro señor, Felipe IV, fechada el 11 de diciembre de 1649, María Nieto defiende la claridad de su estilo entrando incluso en discusión sobre el estilo culterano: "Quando todos procuran afectar escuridad, procuré que mis numeros fuessen inteligibles»; la madrileña se crece y se atreve incluso a enjuiciar sus modelos (Estacio Papin, Catulo, Marino, Zárate, Pantaleón de Ribera), si bien luego, escudada en el socorrido recurso de la falsa modestia, consustancial por tradición a su condición femenina, repliega velas, pero ahí queda su opinión: «Mas ¡valgame Dios! donde camino por senda que no entiendo, juzgando de tan grandes hombres, y más escribiendo a nuestro Livio español, como si yo fuera mas que para açer bainillas» ${ }^{47}$.

El 27 de mayo de 1649, Ana Francisca Abarca de Bolea también informa a Andrés de Uztarroz por carta de la marcha de sus primeros trabajos literarios, concretamente de la redacción de las Catorce Vidas de la orden del Císter (1655); en breves líneas, le expone el plan de la obra, comenta las dificultades, el estilo y el método de trabajo y le pide materiales para la elaboración de la

que son nueve las Musas. / ¿Cuánto se engañan! / Pues he aquí la décima Musa: Safo de Lesbos», recogido por Carlos García Gual, Antología de la poesía griega, Madrid, Alianza Editorial, 1980, p. 139. La consecución de este honor es fruto no sólo del empeño de las Musas, sino también del ingenio y del estudio diligente de Safo que le franquean el paso por los lugares peligrosos y despeñadizos del Parnaso hasta llegar a la morada de las Musas, como comenta Boccaccio en su De mulieribus claris (véase Gloria Boscaini, La traduzione spagnola del "De mulieribus claris», Verona, Università degli Studi di Verona, 1985, pp. 119-120). Marta de Nevares, Oliva Sabuco, Juliana Morella, Bernarda Ferreira de la Cerda, María de Zayas, Ana Caro, Cristobalina Fernández de Alarcón, entre otras, dan nombre y obra en el XVII a la décima musa por deseo de Lope, Pérez de Montalbán, Alonso Castillo Solórzano, Vélez de Guevara, Jerónimo de Parros o Juan de Páez de Valenzuela.

46. Véase Ma de los Ángeles Campo Guiral, Doña Ana Francisca Abarca de Bolea, Zaragoza, Departamento de Cultura y Educación, 1993, pp. 76-78. Las «Octavas a la Purificación de la Virgen» aparecen incluidas con ligeras variantes en la Vigilia y octavario de San Juan Baptista, ed. Ma de los Ángeles Campo Guiral, Huesca, Instituto de Estudios Altoaragoneses, 1993, pp. 61-65.

47. Ibid., p. 649. 
Vida de Santa Mafalda. La tímida Ana Francisca Abarca, que en la carta de 1645 apenas se atrevía a dirigirse al erudito con unas décimas para su libro de los Santos Justo y Pastor, ahora discute con él el plan de esta hagiografía femenina ${ }^{48}$. El mismo hecho de que ella reconozca en esta carta que «habré menester del apoyo de los amigos» para que crean que es obra suya, habla a las claras de las dificultades que habían de franquear las escritoras para llegar al público, pero también de su orgullo y de su clara conciencia autorial. Frente a la medieval Teresa de Cartagena, enfrentada al mismo problema, Ana Francisca encuentra en su mentor Andrés de Uztarroz, en Manuel de Salinas y en general en el grupo lastanosino el refrendo necesario para salir con las debidas garantías a la palestra pública ${ }^{49}$.

En cualquier caso, lo que está claro es que las escritoras emplean las mismas estrategias de legitimación y los mismos mecanismos que los hombres para darse a conocer. En este sentido, las cartas de estas escritoras cruzadas con Andrés de Uztarroz han de verse en el conjunto de su rico epistolario, para advertir claramente que actuaban como los hombres buscando la "crítica» de un lector selecto, el respaldo y el visto bueno de ingenios reconocidos como el cronista del reino de Aragón. También ellas se someten al juicio individualizado y autorizado, antes que al del público general, para después alcanzar gracias a la imprenta el reconocimiento y la notoriedad entre sus contemporáneos. Presumiblemente María Nieto siguió la misma estrategia de legitimación no sólo con Andrés de Uztarroz sino también con otros autores, como puede comprobarse en las piezas preliminares de sus Lágrimas a la muerte de la Augusta Reina N. señora Doña Isabel de Borbón, en las que, a falta de otros versos laudatorios que los de Pedro Rosete, aduce como

48. Las décimas, hoy perdidas, las había compuesto con la intención de adornar el libro del cronista sobre el martirio de los jóvenes santos Justo y Pastor, figuras que se habían convertido en un fecundo tema de inspiración literaria como demuestra Claude Chauchadis, «El Mounumento de los santos mártires Justo y Pastor, de Juan Francisco Andrés de Uztarroz: una obra entre hagiografía y arqueología», estudio introductorio que, junto al de Fermín Gil Encabo, encabeza la edición facsimilar del Monumento de los santos mártires Justo y Pastor, Huesca, Instituto de Estudios Altoaragoneses, 2005, pp. VIII-IX. Las Catorce Vidas de la orden del Císter han sido estudiadas por José Miguel Oltra, "La hagiografía como pretexto autobiográfico en Ana Francisca Abarca de Bolea", en La recepción del texto literario (Coloquio Casa de Velázquez-Departamento de Filología Española de la Universidad de Zaragoza, Jaca, abril de 1986), ed. Jean-Pierre Étienvre y Leonardo Romero, Zaragoza, Secretariado de Publicaciones de la Universidad de Zaragoza, 1988, pp. 77-103.

49. Comenta esta red de relaciones Ma Ángeles Campo Guiral, «Ana Francisca Abarca de Bolea y el círculo lastanosino", en La cultura del Barroco. Los jardines: arquitectura, simbolismo y literatura, pp. 29-41. Para su amistad con el canónigo y poeta Manuel de Salinas, véase Pablo Cuevas Subías, Manuel de Salinas, Obra poética, Zaragoza, Prensas Universitarias de Zaragoza, 2006, p. LVIII y ss. 
epitextos elogiosas epístolas de Francisco López de Zárate y Manuel de Faria y Sousa; cartas de respuesta parejas a las de Andrés de Uztarroz en las que estas autoridades reconocidas animan a la joven promesa a dar a la imprenta su obra ${ }^{50}$. De esta forma, a través de las cartas, María Nieto consiguió cierta proyección social como escritora. Gracias a Andrés de Uztarroz, logró darse a conocer en el círculo aragonés, fue requerida para participar en certámenes locales, llegó a Filhol y a Gracián, quien al recoger sus versos en la Agudeza le otorgó el prestigio que buscaba y, de algún modo, canonizó su obra. Si su relación con el grupo aragonés está contrastada, no consta que existiera, sin embargo, con Tomasina Francés, con Ana Abarca o con otras escritoras aragonesas, entre las que no se advierte resto alguno de una conciencia grupal que podría haberse convertido en otro mecanismo de afirmación personal. Aparentemente todas ellas parecen vivir en un total aislamiento.

\section{ANDrÉS DE UZTARroZ, Historiador DE LA ESCRITURA FEMENINA}

Como se ve, Andrés de Uztarroz tuvo un conocimiento directo de la escritura femenina, siguió de cerca los pasos de estas autoras, poetas y prosistas, supervisó y dirigió de algún modo su producción y acabó por encumbrarlas incluyéndolas, junto a otros vates aragoneses, en el Aganipe de los cisnes aragoneses, una historia de la poesía aragonesa del momento en la línea de los poemas panegíricos-censorios. Antes de componer este poema, es posible que Andrés de Uztarroz barajara también en algún momento la idea de «historiar» la relación de las mujeres con las letras y en ella la escritura femenina. Dos datos resultan significativos a este respecto. El primero lo

50. María Nieto sigue la estrategia de alcanzar primero la sanción del «severo censor» antes de dar la obra a la imprenta, mecanismo de legitimación comentado por Pedro Ruiz, "Aristarcos y Zoilos: límites y márgenes del impreso poético en el siglo XVI», BHi, 102(2000), pp. 339-369, p. 355. En el caso de las Lágrimas a la muerte de Isabel de Borbón, aduce en sus preliminares las cartas personales enviadas por Francisco López de Zárate y Manuel Faria y Sousa, epístolas en las que ambos autores encarecen la calidad de los versos de una jovencísima poeta de entonces apenas catorce ańos. Cito por el ejemplar de Córdoba, Biblioteca Pública del Estado/Biblioteca Provincial, 3/72 (5), que reúne todas las piezas preliminares y que me permiten modificar las fechas de su nacimiento aportadas por Serrano y Sanz en sus citados Apuntes para una biblioteca de escritoras españolas. La carta de Uztarroz estaría en la línea de éstas y para María Nieto tendría el mismo valor. El mecenazgo de Uztarroz y la madrileña ya lo apuntó Isabel Barbeito Carneiro, "¿Por qué escribieron las mujeres en el Siglo de Oro?», Cuadernos de Historia Moderna, 19 (1997), pp. 183-193, p. 186, a quien se debe la aproximación más reciente a su vida y obra en su tesis doctoral, Escritoras madrileñas del siglo XVII: estudio bibliográfico-crítico, Madrid, Universidad Complutense, 1986, 2 vols., pp. 674-690. 
hallamos en la redacción del Museo antiguo y moderno de los historiadores de Aragón y su corona, iniciada en 1639, obra en la que pretendía historiar a los historiadores aragoneses ${ }^{51}$. En la misma recoge un folio titulado: «Mugeres insignes en letras Españolas» (fol. 225), una humilde hoja de papel en la que Andrés de Uztarroz iba recopilando en diferentes tiempos, como se deduce de la caligrafía, de los tipos de tinta y de su asistemática anotación, nombres de mujeres destacadas en las letras. Como reza el título, su intención no era en principio reunir tanto mujeres escritoras cuanto mujeres destacadas en las letras, el mismo criterio que venían siguiendo los repertorios de mujeres al uso y que asumirá también luego Nicolás Antonio en el apéndice Gynaeceum que cierra su Bibliotheca. La intención, por otro lado, era la misma que animaba a su amigo el presbítero Filhol, ocupado en la confección de un volumen "de las mugeres ilustres en letras» (fol. 226), a cuyo proyecto el cronista había contribuido, como ya hemos visto, remitiéndole los versos de María Nieto. No deja de ser sintomático que la carta antes citada, en la que Uztarroz da cuenta de ello a la poeta madrileńa, aparezca recogida en el folio 226 de este manuscrito del Museo antiguo y moderno, lo que parece indicar una sintonía de intereses con el proyecto de Filhol.

En el caso de Andrés de Uztarroz, el registro de las «mugeres insignes en letras espańolas» va acompañado de la fuente de referencia en la que aparece citada, de manera que el cronista va repasando algunos de los «repertorios» o inventarios conocidos entonces sobre la escritura femenina. A partir de las fuentes referidas, de [Alonso García] Matamoros, Juan Costa, [Esteban] Garibay, Diego Ramírez [Pagán], Lope de Vega, Vicente Espinel, Bartolomé Leonardo de Argensola, [Lucio Marineo] Sículo, el cronista aragonés reúne los nombres de veinticuatro mujeres señaladas en las letras: Ángela Zapata, Ana de Villegas, Cecilia de Arellano, Isabel la Católica, Isabel de Vega, Isabel Pellicer, Clara Barrionuevo, Isabel de Rivadeneyra, Laurencia Zurita, Cristobalina [Fernández de Alarcón], Juliana Morella, Ana de Zuazo, María de Zayas, Francisca de Guzmán, Isabel Coello, Catalina de Solís, Juana de Contreras, Ana Cerbatón, Ana de la Madre de Dios, Cipriana de San Juan y la Brit, María Nieto, Lucía Materna y Ana de Bolea, en algunos casos con pequeñas glosas biobibliográficas identificatorias. A las fuentes hasta entonces más habituales (Marineo Sículo, Alonso García Matamoros o Lope de Vega), Andrés de Uztarroz añade por primera vez otras. En primer lugar, las de los cronistas Juan Costa, cuya obra Gobierno del ciudadano menciona expresamente como fuente, Esteban Garibay (Compendio historial,

51. Museo Antiguo y Moderno, año 1639, Madrid, Biblioteca Nacional, Ms. 9457, fol. 225. Ricardo del Arco, op. cit., I, p. 170, ofrece una breve selección de las citadas. 
a propósito de la cita de Isabel la Católica) ${ }^{52}$ y Bartolomé Leonardo de Argensola, aunque en este caso la fuente no es ninguna obra historiográfica, sino las Rimas ${ }^{53}$. A todas ellas suma también las de los poetas Diego Ramírez Pagán (Rimas, Triunfo de amor) ${ }^{54}$ y Vicente Espinel (Rimas) ${ }^{55}$. No requiere autoridad la mención de nombres como «María Nieto de Aragón en Madrid» $\mathrm{y}$ «D. Ana de Bolea Abadesa de Casvas», a las que conocía bien ${ }^{56}$.

52. La obra de Juan Costa, Gobierno del ciudadano, conoció varias reediciones, siendo la última, publicada en Zaragoza en 1584, la más ampliada. Cito por ella en la edición de Antonio Ubach Medina, Zaragoza, Institución «Fernando el Católico», 1998, pp. 289-290. La mención aparece en el «Diálogo segundo, do se trahen muchos exemplos de damas que fueron mucho en armas y letras y se trata de sus loores». Las alaba como «únicas en las lenguas latina, toscana, francesa y portuguesa», p. 290. De esta fuente Uztarroz pudo tomar el ejemplo de Ángela Zapata, citado también por Costa con la autoridad de Alfonso García Matamoros en su Pro adserenda hispanorum eruditione, uno de los repertorios habituales de la época que cito por la edición de José López de Toro, Madrid, CSIC, 1943, p. 229. Para el ejemplo de Isabel la Católica opta, en cambio, por la autoridad del también cronista real Esteban de Garibay, autor del Compendio historial de España (1570-1572).

53. Bartolomé Leonardo de Argensola, Rimas, ed. José Manuel Blecua, Madrid, EspasaCalpe, Clásicos Castellanos, 1974, vol. 2, p. 120. Según la información aportada por Serrano y Sanz en el apéndice de sus Apuntes, p. 654, tras enviudar, Catalina Solís tomó el hábito de religiosa franciscana (Sor Catalina de las llagas) y murió en 1617. Le atribuye varias composiciones religiosas, a las que hay que sumar el soneto incluido por el aragonés en sus Rimas.

54. La anotación reza: «Doña Isabel de Vega con las Rimas de Diego Ramírez pone un soneto, el mismo en el Triunfo de amor celebra a d. Isabel Pellicer, dama valenciana». La fuente en este caso es la Floresta de varia poesia (1562) de Diego Ramírez Pagán, ed. Antonio Pérez Gómez, Barcelona, Selecciones Bibliófilas, 1950, p. 60, donde figura efectivamente un soneto firmado por Isabel Vega, la Belisa a la que toma también como interlocutora en otros poemas. La cita del Triunfo de amor se refiere al Tropheo de amor y de damas, un extenso poema en el que Ramírez Pagán elogia a damas valencianas y entre ellas a Isabel Pellicer, «la más sabia honesta y bella / de quantas Phebo en su ribera mira», p. 219.

55. Andrés de Uztarroz apunta: «Vicente Espinel celebra en sus Rimas fol. 48 a d. Francisca de Guzmán, D. Isabel Coello, d. Ana Suaço». El cronista toma la referencia en este caso del canto segundo del poema La casa de la memoria, incluido en sus Diversas rimas, ed. Dorothy Clotelle Clarke, New York, Hispanic Institute, 1956, p. 95, un poema en la línea del parnaso cervantino, donde cita a estas tres mujeres destacadas en la música junto a la noble Agustina Torres, en cuyos salones salmantinos se reunió con los mejores músicos de la época. Agustina de Torres era madre de Ana de Zuazo y de Catalina de Zamudio, autora del soneto laudatorio que figura al frente de las Diversas rimas de Espinel, véase al respecto Juan Carlos Ayala Ruiz, «Vicente Espinel: evidencias de una obra musical hoy desconocida», Hoquet. Revista del Conservatorio Superior de Música de Málaga, 4 (2006), pp. 5-23.

56. La inclusión de ambas al final de la lista revela la incorporación paulatina de datos a una obra en marcha. Del Museo nos han llegado dos copias fechadas respectivamente en 1639 y 1648. La mención de la madrileńa Nieto resulta difícil en 1639, pues aunque fue una 
El interés por historiar la escritura femenina se evidencia también en el Elogio al autor del "Genio de la Historia", Jerónimo de San José, 1651, en el que Andrés de Uztarroz alaba a su promotor, el segundo Marqués de Torres, Luis Abarca de Bolea y Castro ${ }^{57}$. Repasando su ilustre genealogía, el cronista menciona a su tía, doña Ana Francisca Abarca, cuya figura y obra había seguido de cerca, anuncia la impresión de las Vidas de algunas santas de su Religión y, lo que resulta más interesante, la considera una autora digna de entrar en los anales de la historia. Juan Francisco Andrés ve la escritura femenina desde la proyección histórica:

su nombre en los venideros siglos y en los presentes dará materia a los escritores para discurrir en sus prendas, como la dieron a Lucio Marineo Sículo, doña Ana Cerbatón, dama de la Serenísima Reina Doña Germana de Fox, doña Juana Contreras y doña Lucía Materna; a Alonso García de Matamoros, doña Ángela Zapata, doña Ana de Osorio, Isabel Joense, natural de Barcelona, y Sigea de Toledo; a Diego Ramírez, doña Isabel Pellicer; al maestro Vicente Espinel, doña Francisca de Guzmán, doña Isabel Coello y doña Ana Zuazo, y a Lope de Vega tantas mujeres doctas, como refiere en su Laurel de Apolo, y otros muchos escritores, que no acaban de engrandecer su ingenio, sutileza y aplicación a las artes liberales y ciencias. El sujeto, de quien hablamos [Ana Francisca Abarca de Bolea], merece compararse con estas heroínas de la elocuencia, como sus escritos lo publicarán.

Como puede comprobarse, Andrés de Uztarroz recurre a las mismas fuentes que en el Museo antiguo y moderno, ordenadas ahora de forma cronológica: (Marineo Sículo, 1530), Alonso García Matamoros (1553), Diego Ramírez (1562), Vicente Espinel (1591) y Lope de Vega (1629). En este caso, amplía, sin embargo, la lista de García Matamoros (Pro adserenda hispanorum eruditione, 1553), pues al nombre antes citado de Ángela Zapata, añade los de Ana Osorio, Isabel Joense y Luisa Sigea, suprimiendo en cambio la enumeración de las citadas por Lope en el Laurel de Apolo y omitiendo el nombre de María Nieto y el de las monjas aragonesas. Las escritoras merecen ser historiadas, forman parte de la historia y configuran una historia literaria que él intuye y comienza modestamente a pergeñar. Por su propia formación de historiador y poeta, Andrés de Uztarroz estaba capacitado para escribirla,

autora precoz que comenzó a publicar a los catorce años, en ese año sólo contaba con ocho o nueve de edad.

57. Fr. Jerónimo de San José, Genio de la Historia. Ensayo bio-bibliográfico y notas por Fr. Higinio de Santa Teresa, Vitoria, Ediciones «El Carmen», 1957, pp. 227-228. El Genio de la Historia lo publica en 1651 el Marqués de Torres, en Zaragoza, en la imprenta de Diego Dormer. 
podía acopiar fuentes y remontarse al pasado, pero sobre todo podía dar fe y testimonio del momento presente por conocerlo bien y seguirlo de cerca. No sabemos si en algún momento barajó en firme esta posibilidad, pero el mero hecho del acopio de materiales, todavía sin cribar, habla por sí solo del interés por el tema. El proyecto no llegó a materializarse. En el cajón quedaron también otros trabajos inconclusos del cronista, p.e. unos apuntes para la confección de una "Biblioteca de Escritores Aragoneses», notas en las que no había registrado todavía a ninguna mujer y que quizá no cobraron forma por solaparse con la Bibliotheca de Nicolás Antonio.

En relación con el bibliógrafo sevillano, no hay que olvidar la comunicación epistolar que, propiciada por Pellicer, ambos mantuvieron a partir de $1652^{58}$. Nicolás Antonio tomó a Andrés de Uztarroz como corresponsal $y$, en diferentes cartas, le requirió datos sobre ingenios aragoneses para el proyecto de su Bibliotheca, asegurándole la máxima transparencia en su empleo. El cronista adjuntó estas listas a los apuntes de su citada «Biblioteca de Escritores Aragoneses», pero en ellas, como he dicho, no requería información sobre autoras aragonesas. Ninguna aparece entre las cuarenta y siete citadas en la Bibliotheca ni en las cincuenta y una mencionadas en el Gynaeceum, a excepción de Luisa de Padilla, condesa de Aranda que, aunque burgalesa de nacimiento, vivió y desarrolló su obra en tierras aragonesas ${ }^{59}$. Pese a ello, es posible que Nicolás Antonio consultara las anotaciones de Andrés de Uztarroz y siguiera algunas de las fuentes recogidas por el cronista, posiblemente las de Juan Costa, Vicente Espinel o Bartolomé Leonardo de Argensola. El apresurado final del Gynaeceum, tras la entrada de Valentina Pinelo, recuerda, en este sentido, el cierre del elogio de Ana Francisca Abarca en el Genio de la Historia con la mención de Espinel y Bartolomé Leonardo de

58. Las relaciones epistolares mantenidas por el bibliógrafo sevillano con los cronistas aragoneses las comenta Leonardo Romero Tobar, «Nicolás Antonio y los aragoneses contemporáneos», Cuadernos de Aragón, 20(1987), pp. 205-210. Algunas de las cartas las recoge Ricardo del Arco en su obra ya citada.

59. Nicolas Antonio, Gynaeceum Hispanae Minervae, apéndice a su Bibliotheca Hispana Nova sive hispanorum scriptorum qui ab anno MD ad MDCLXXXIV floruere notitia, tomus secundus, Matriti, Apud Viduam et Heredes Joachimi de Ibarra, MDCCLXXXVIII, reprod. facsímil, Madrid, Visor Libros, 1996, pp. 343-353. Como bien explica François Géal, "Nicolás Antonio juge de la femme de lettres à travers la Bibliotheca Hispana Nova", en Relations entre hommes et femmes en Espagne aux XVI et XVII siècles, ed. Augustin Redondo, Paris, Publications de la Sorbonne, 1995, pp. 39-52, en el Gynaeceum el concepto de mujer autor cede al de mujer de letras, mujeres que merecen ser citadas por su saber. Sobre el mismo, véase también Lola Luna, "Las escritoras en la Bibliotheca de Nicolás Antonio», art. cit., pp. $28-40$. 
Argensola como fuentes: «a Vincentio Espinel Francisca de Guzman, atque eadem Anna Zuazo : a Bartholomaeo Leonardo de Argensola Catharina de Solis» (p. 353).

De todos estos proyectos historiográficos, Andrés de Uztarroz sólo concluyó el Aganipe de los cisnes aragoneses, si bien no llegó a la imprenta hasta un siglo después por empeño del ilustrado Ignacio Jordán de Asso (1781). En el poema cataloga una docena de escritoras aragonesas de escasísima obra y hoy unas auténticas desconocidas, a excepción de Ana Francisca Abarca de Bolea y, en el mejor de los casos, de Luisa de Padilla, citada indirectamente a propósito del agustino Fray Pedro Enrique Pastor, a cuyo nombre circularon parte de sus obras. Guiado más por la selección que por la exhaustividad, pues muchas eran las poetas que conocía y podía haber antologado, Andrés de Uztarroz sólo canoniza a unas pocas. De los certámenes con los que directamente estuvo relacionado, recoge el nombre de Ana Vincencia de Mendoza y el de su prima Tomasina Francés; incluye asimismo a las citadas en el Museo antiguo y moderno: la madre Ana de la Madre de Dios (en el siglo Ana Casanate y Espés, de Tarazona), Cipriana de San Juan de la Brit (Zaragoza) y Ana Francisca Abarca de Bolea. Sin duda la monja de Casvas es la mejor conceptuada, calificada de nuevo como «Musa décima» e «insigne Terracina», una comparación con la escritora italiana Laura Terracina ya empleada por Lope en relación con otras autoras y que, a diferencia de la imagen parnasiana, representa un signo de modernidad y un deseo de equiparar la escritura femenina a la de las modernas italianas; algo similar a lo que después hará Nicolás Antonio proponiendo al frente de su Gynaeceum a la italiana Lucrecia Marinelli como modelo ejemplar de escritora acorde con los nuevos tiempos.

El Aganipe de los cisnes aragoneses es el cuadro oficial que inmortaliza el parnaso aragonés femenino del momento, de mediados del siglo XVII, ligeramente ampliado después por Félix Latassa con la referencia de escritoras religiosas descubiertas en su visita a conventos y monasterios aragoneses. Tras el cuadro oficial se esconde, sin embargo, una historia mucho más rica de lo que representa, un conocimiento directo de la escritura femenina y una red de relaciones que ayudan a legitimar a las escritoras y a que ellas mismas, con diferentes estrategias, consigan hacerse, como Safo, un hueco en el Parnaso. 